\title{
A Framework for Studying Organizational Innovation in Research Libraries
}

\section{Ronald C. Jantz}

The objective of this paper is two-fold: to propose a theoretical framework and model for studying organizational innovation in research libraries and to set forth propositions that can provide directions for future empirical studies of innovation in research libraries. Research libraries can be considered members of a class of organizations referred to here as institutional nonprofits. As such, these organizations inherit many of the innovative properties that are associated with the broader sector of service organizations. However, institutional nonprofits have unique characteristics that distinguish them from other service organizations such as government agencies and for-profit service firms. In this paper, institutional theory is used to explain the forces that are acting on the research library. Research from organizational learning, structural contingency theory, and typologies of service organizations are used to establish a more encompassing innovation framework. Based on the literature review, the theoretical framework, and empirical studies, this paper presents a process model and propositions that characterize how the research library might innovate. These propositions can be tested in empirical studies to develop a fuller understanding of innovation in research libraries.

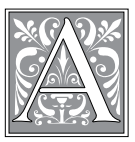

fundamental question for innovation research is to explain how innovations occur. Innovation can be studied at many different levels - the individual, the work group, the organization, and at industrial or cross-national levels. This research will focus on organizational innovation in a relatively understudied sector: nonprofit, service organizations (and, more specifically, research libraries) ${ }^{1}$ In general, innovativeness is a desirable trait for social organizations. In a commercial or for-profit firm, an innovation may be initiated because there is an opportunity to increase profit or gain a competitive edge. For nonprofits, innovation is motivated by the desire to advance the public good. In a research library, the public good consists of the activities to support scholarly communication and the advancement of knowledge for faculty, students, staff, and the broader public community. These initiatives support the mission of the parent institution to produce informed citizens who can participate in the democratic

Ronald C. Jantz is Digital Library Architect at Rutgers University Libraries; e-mail: rjantz@rci.rutgers. edu. (C) 2012 Ronald C. Jantz, Attribution-NonCommercial (http://creativecommons.org/licenses/by-nc/3.0/) CC BY-NC 
process. Innovation literature has defined two factors that motivate organizations to innovate: organizations innovate to survive and organizations innovate to thrive over the long term. ${ }^{2}$ From the survival perspective, a research library might innovate because of significant reductions in funding from the parent institution. Gaining a competitive advantage might relate to the competition for students and the capability to offer new services. In a previous study, interviews of university librarians showed strong support for these different aspects of innovation; however, these same library leaders have also voiced concern about how to foster an innovative climate in their institutions. ${ }^{3}$

Rogers defines an organization as follows: "An organization is a stable system of individuals who work together to achieve common goals through a hierarchy of ranks and a division of labor." ${ }^{4}$ Innovation is defined as the introduction into the organization of a new product, a new service, a new technology, or a new administrative practice; or a significant improvement to an existing product, service, technology, or administrative practice. ${ }^{5}$ An underlying premise in the proposed framework is that the innovation process differs significantly across three general sectors: manufacturing, services, and nonprofits. A rich and varied tradition of sectoral studies clearly reveals that these sectors differ in terms of knowledge base, the actors involved, the relevant institutions, and the innovation process. ${ }^{6}$ As in the services, for-profit sector, nonprofits can take on many different characteristics. The focus in this paper is on those nonprofit organizations that have a well-established institutional and professional framework with traditions and regulations that are more formal and binding than is found in the larger class of service organizations. These organizations will be referred to here as institutional nonprofits, a class that includes universities, colleges, research libraries, high schools, and, perhaps, even certain research hospitals and welfare organizations.

\section{Theoretical Background}

The Service Organization. The classical view characterizes the service organization as peripheral and unproductive. This view can be traced back to the 18th century and to the writings of Adam Smith as quoted by Gallouj and Savona: “... services generally perish in the very instant of their performance, and seldom leave any trace of value behind them, ..."7 This quote highlights a persistent view that services do not produce any physical output and are, therefore, considered unproductive. As a result of some of these lingering historical views, innovation in service organizations has only recently emerged as an important research area. Miles notes that services are not only important economically, but also play an important role in innovation processes as agents of transfer and sources of innovation for other sectors. ${ }^{8}$ The service sector includes the most concentrated, knowledge-intensive and information-intensive services in the modern industrial economy. ${ }^{9}$

There is obviously huge diversity in the service model ranging from personal services (for instance, hair dressing) to very large firms in areas such as telecommunications and real estate. Barras' model of the reverse product cycle (RPC) is often cited as the first theoretical approach to innovation in service organizations. In this model, the product cycle acts in the opposite direction from that of manufacturing organizations. ${ }^{10}$ Barras argues that the RPC is enabled by information and communication technologies that are developed elsewhere and then adopted by service organizations. For example, service firms may transfer an information technology product from a manufacturing firm and initially use this technology to improve the efficiency of their backoffice processes. Knowledge gained from these incremental innovations might then be used to improve the quality of services offered to clients. As a final stage in the reverse product cycle, the same technology might be incorporated in a more radical and totally new service operation. 
In addition to developing the model of the reverse product cycle, Barras noted other differences in service organizations including intangible products, minimal formal R\&D, and the close linking of product and process innovations. Hipp and Grupp further refine Barras' theory by noting that legal and professional regulation is at the core of many service organizations and delivery of a service typically involves client participation. ${ }^{11}$ Client participation and professional regulation are major aspects of the service model and the institutional environment in which we find research libraries. Gallouj and Savona note that the RPC model does not account for service innovations that have no technology component, an important dimension to examine for research libraries. ${ }^{12}$

Several examples of the RPC are useful at this juncture. As Barras has indicated, the RPC can be initiated by the transfer of information technology from organizations external to the library. Within the last few years, instant messaging and mobile technology have been embraced by research libraries to augment reference service and to deliver Web services on the technology platforms that students prefer. A variety of similar incremental innovations have been launched to take advantage of mobile technology. For example, a student can use her smartphone to scan QR (quick response) codes, resulting in a transfer to special library services. From these early incremental innovations, we are likely to see the cycle progressing to more radical innovations in which digital books from the library collection are delivered on modern platforms using iPADs and similar devices. One can trace similar trends in database technology that was used initially in back-office applications. Initially, these applications improved the quality and efficiency of administrative processes and helped library staff become familiar with the technology. Later developments included more radical applications including the use of database technology in the online catalog and, more recently, in institutional repositories.
The Institutional Framework. Many of the nonprofit organizations are embedded within an institutional framework. The study of institutions has experienced a renaissance with a more recent emphasis on the nonprofit sector and organizational analysis. ${ }^{13}$ DiMaggio and Powell's theory of institutional isomorphisms provides a promising framework for understanding research libraries as a recognized area of institutional life. Once a set of organizations emerges as a field, a paradox results in which rational actors work to make their organizations similar. These researchers argue that structural change is driven less by competition, but rather more by bureaucratization that is making organizations more similar without making them more efficient. They define three isomorphic processes that are leading to this result. These three mechanisms of institutional isomorphic change are coercive (resulting from both formal and informal pressures exerted on organizations upon which they are dependent), mimetic (resulting from standard responses to uncertainty), and normative (a force associated with professionalism). ${ }^{14}$

In the organizational context of research libraries, we might expect a coercive force to emanate from state government or a regulatory agency and the associated political and budget control. When an organization faces uncertainty introduced by the environment and rapidly changing technology, a mimetic force can cause imitation where the organization adopts services or products that appear to be successful in other similar institutions. This mimetic behavior can produce successful, incremental change in a short time with minimal cost and effort. A very strong normative force operating on a research library is professionalism that resides in formal education and professional networks.

According to DiMaggio and Powell, two aspects of professionalism result in normative isomorphic tendencies: 1) the vesting of formal education and legitimation in a cognitive base produced by specialists; and 2) the growth and 
elaboration of professional networks that span organizations. ${ }^{15}$ In a particular relevant assertion, these researchers note that "many professional career tracks are so closely guarded, both at the entry level and throughout the career progression, that individuals who make it to the top are virtually indistinguishable." In developing hypotheses regarding environmental uncertainty and bureaucratic structures, DiMaggio and Powell assert that these forces often lead organizations to resemble each other in structure, culture, and output. Within an institutional context, these isomorphic forces suggest that the more uncertain the relationship between means and ends, the greater the extent to which an organization will model itself after organizations it perceives to be successful. DiMaggio and Powell also hypothesize that "the greater the reliance on academic credentials in choosing managerial and staff personnel, the greater the extent to which an organization will become like other organizations in its field." 16

\section{Organizational Innovation Concepts}

One of the major difficulties in the innovation literature is the confusion in terminology and lack of consistency in classifying innovations. To explain some of the inconsistencies of single dimension innovation studies, scholars have developed structural theories of innovation that have come to be known as the middle range theories of organizational innovation. ${ }^{17}$ These three theories deal respectively with types of innovations (administrative or technical) ${ }^{18}$ attributes of an innovation (incremental or radical), ${ }^{19}$ and ambidexterity (the initiation and implementation stages of innovation). ${ }^{20}$ The definitions and classifications that are inherent in these theories are discussed below.

Innovation Types. Innovations can be classified into two basic types: administrative and technical. ${ }^{21}$ According to Damanpour, the distinction between technical and administrative innovations is fundamental since it reveals essential differences in the nature of innovation in organizations..$^{22}$ The technical innovation is directed outward to the client and relates to new services and the technology used to produce these services. In contrast, the administrative innovation is directed inward and relates to administrative processes, budget control, and human resources (such as the reward system).

Innovation Characteristics. The service innovation model discussed previously suggests that innovation in nonprofits will be predominantly of the incremental type. The premise of this study is that the increasing turbulence and uncertainty in the external environment will cause more radical innovation to occur in research libraries. Therefore, a most important characteristic for research deals with the extent of change of an innovation, which varies along a continuum from incremental to radical. According to Zaltman, a radical innovation is always "to some extent disruptive of the status quo" and involves changes in the organization's subsystems, values, incentives and power. ${ }^{23}$ Radical innovations involve new knowledge that is used to make fundamental changes in a product or process technology, whereas an incremental innovation uses existing knowledge to create minor improvements in a product or process technology. Radical innovations represent a clear departure from existing practice whereas incremental innovations are more routine and support existing practice. Although the incremental and radical concepts represent a continuum, this study will view these concepts as endpoints or polar opposites on a continuum. ${ }^{24}$

Stages of Innovation. In characterizing the ambidextrous organization, Duncan divides the organizational innovation process into two stages: initiation and implementation. The initiation stage consists of three substages: a) the knowledge-awareness substage, b) the attitude-formation substage, and c) the decision substage. The implementation stage consists of two substages: a) the initial implementation substage and $b$ ) the continued-sustained 
implementation substage. These stages form part of the proposed innovation process model (see figure 1) and will be discussed in more detail in the next section..$^{25}$

Organizational Structure: Complexity, Centralization, and Formalization. Burns and Stalker provide the original insight regarding organizational structure and the environment. A stable environment leads to mechanistic structures with centralized and hierarchical controls whereas change and turbulence in the external environment leads to flattened structures and diversity of professional knowledge and skills. ${ }^{26}$ Damanpour and Gopalakrishnan have further refined the role of the external environment and the relationship to organizational innovation. Their framework posits two dimensions of the environment: stable/unstable and predictable/unpredictable. These researchers place universities, colleges, and research libraries in the stable/predictable quadrant, an environment that leads largely to mechanistic organizational structures and incremental innovation. ${ }^{27}$

The degree of organizational complexity or job specialization is a key concept in innovation literature. Zaltman et al define this important construct as consisting of two dimensions: the number of occupa- tional specialties and functional diversity or the number of units in an organization. ${ }^{28}$ To cope with the uncertainty in the environment, leaders will typically increase organizational complexity by recruiting people with different knowledge and skill sets and by creating new functional units.

Centrality or hierarchical aspects of an organization refer to the locus of authority and the degree to which members of the organization are involved in decision making. A more centralized organization is one in which the decision processes are characterized as "top-down." Since there continues to be much debate on the benefits of centralization versus decentralization, this area is an important one to study. Hamel and Prahalad would say that it's the bureaucracy, multiple levels of approval, and lack of personal freedom that "bottle up innovation." 29

Zaltman et al defines formalization as the emphasis an organization places on following specific rules and procedures. ${ }^{30}$ Hage and Aiken describe formalization as a focus on rules and the resultant efficiency that is brought about by rule enforcement. Rules are closely associated with organizational processes, and a more formalized organization is typically more centralized. Rigid rule observation has

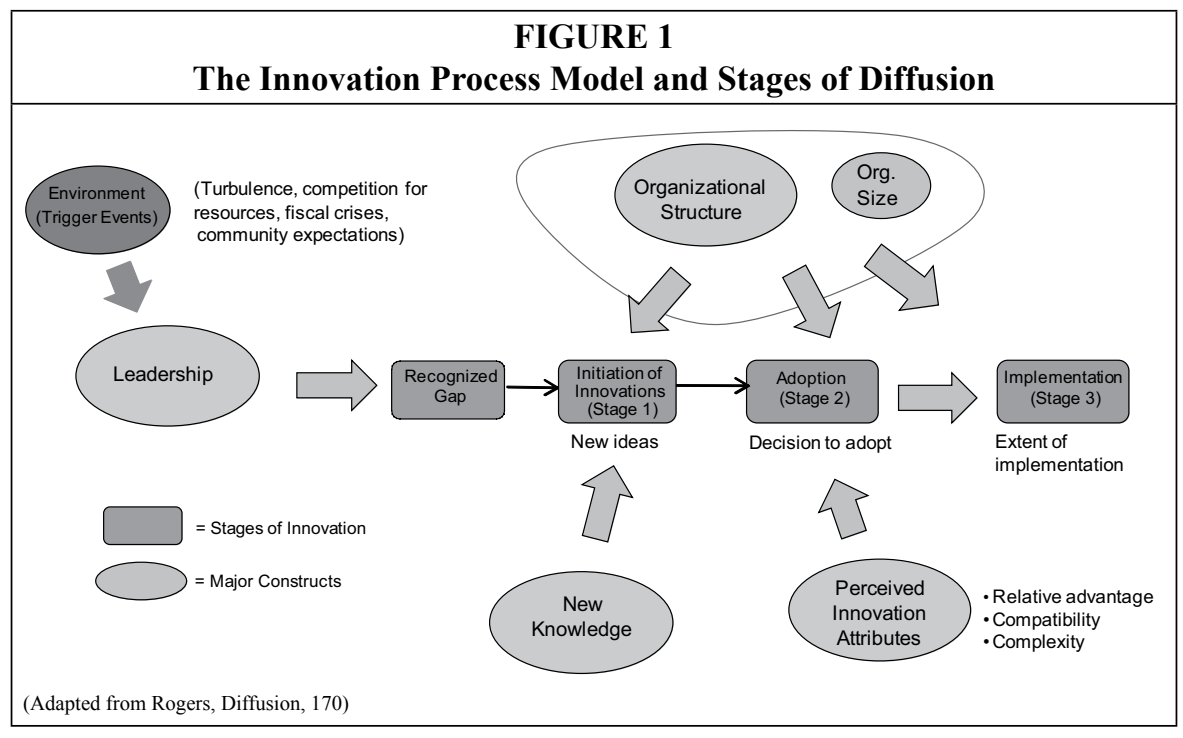


been found to inhibit communication and the flow of ideas. ${ }^{31}$ Although well-defined processes are important to deliver highquality service, a preoccupation with rules and processes does not provide organizational members with the freedom to think independently and propose new approaches.

\section{A Framework and Model for Innovation}

Figure 1 presents an innovation process model that identifies the stages in the diffusion process as well as four major construct groups: leadership, new knowledge, organizational structure, and perceived innovation attributes. This model provides a more encompassing framework by highlighting the combined effects of these constructs and the external environment on the process of organizational innovation.

Three major stages of diffusion are depicted in figure 1: the initiation of the innovation, a decision to adopt, and implementation of the innovation. As defined previously, there are multiple substages for each of these three major stages. ${ }^{32}$ For example, a first step in the initiation stage is organizational awareness of the possibility for an innovation. This awareness is frequently related to leadership and the identification of a performance gap, where the performance gap acts as a motivator to search for solutions that can address an identified need or a new opportunity. New knowledge becomes important at this stage. Innovations originate in novel, new ideas and individual creativity is thought to be an important antecedent of innovation. When new knowledge and ideas intersect with an opportunity or need, initiation of an innovation can occur. The second substage of initiation is that of attitude-formation in which leadership and members of the organization create impressions of the innovation. In the research library, the singular leader and the leadership team become important in attitude formation and the subsequent decision process.
A meta-analysis covering 40 years of research has shown that one of the most consistent indicators of innovation is the leader's positive attitude toward change. ${ }^{33}$

If an innovative idea is congruent with the strategy of the organization, compatible with the culture, and provides a significant advantage, then progression to the next stage-decision to adoptbecomes possible. In the decision stage, there is much information gathering and communication within the leadership team to decide to proceed to the implementation stage.

The third stage-implementationtypically has two substages. In the initial implementation, the innovation is put on a trial basis and evaluated to determine if it is practical for a long-term commitment. The second substage involves a formal commitment in which the organization establishes appropriate processes and policies and possibly makes structural changes to support the innovation. Full implementation occurs when a majority of the potential clients have successfully used the innovation.

As shown in figure 1, perceptions of the innovation have a significant impact on the decision process. Figure 1 identifies "perceived innovation attributes" as a major construct. According to Rogers, an innovation has five perceived attributes that explain different rates of adoption: a) relative advantage (the degree to which an innovation is perceived as better than the idea it replaces); b) compatibility (the degree to which an innovation is perceived as being consistent with the organization's values and culture); c) complexity (the degree to which an innovation is perceived as difficult to understand and use); d) trialability (the degree to which an innovation lends itself to experimenting and prototyping); and e) observability (the degree to which the results of an innovation are visible to others). ${ }^{34}$ In a meta-analysis of empirical studies, Tornatzky and Klein report that studies have consistently shown a positive relationship between innovation adoption and both 
relative advantage and compatibility. In contrast, complexity of the innovation is typically reported as having a negative relationship to innovation adoption. ${ }^{35}$

The process model of figure 1 can be seen as generic and applying to many different types of organizations. Obviously, there are many feedback loops occurring within the three diffusion stages, and the total process can proceed over many months or even years. As will be seen in the following sections, the theoretical framework provides a context to understand more specifically how the process relates to research libraries.

\section{Literature Review}

This section reviews the relatively sparse literature that relates specifically to innovation in libraries. Propositions regarding innovation are then put forth based on previous research and the unique aspects of research libraries. Reynolds and Whitlatch note that there is no comprehensive theory that can be used to study innovation in research libraries. Although there is much published literature on the need for innovation, there still does not appear to be any substantial theoretical approaches to studying innovation in research libraries. ${ }^{36}$

Organizational Structure in Libraries. As indicated in figure 1, the structural dimensions of an organization can affect virtually all stages of the innovation process. Budd asserts that the most common form of organizational structure in research libraries is the hierarchical bureaucracy, which includes the primary functional areas of public services and technical services. ${ }^{37}$ This organizational form provides the structure and control that is desired by library managers. Musman characterizes the library technical services function as consisting of work activities that are geared to specific processes and well-defined tasks, an environment that emphasizes quality and efficiency rather than the generation of innovative or novel ideas. On the other hand, the public services organization can be considered more of a professional bureaucracy where processes are more decentralized and members operate with considerable autonomy. ${ }^{38}$ In a public services organization, incremental or routine innovations emanate from practice, the liaison role, and the client interface.

Based on Hage and Aiken's theory of organizational complexity, Howard presents an analysis of how the impact of organizational structure can affect the rate of innovation in research libraries. In reviewing the research of Hage and Aiken, Howard reports that a key variable that stimulates creativity is organizational complexity, and the critical component of organizational complexity is diversification of knowledge. Diversification of knowledge can be characterized by the number of occupational job titles. For the sample of institutions, Howard selected four research libraries grouped by demographic similarities into two pairs. For this small sample, Howard's study showed mixed results in both the complexity-innovation and centralizationinnovation relationships. ${ }^{39}$

Fowler studied organizational learning and innovation by focusing on a single academic library in which use of the Internet was considered the innovation outcome. In this study, fourteen variables were identified that might have an impact on innovation. Of these variables, professional reading and the number of published articles were significant positive factors affecting innovation, whereas organizational structure was not significant. ${ }^{40}$

Innovation and the Size of Libraries. In a mixed mode analysis of 140 academic libraries within institutions that grant master's and bachelor's degrees, White found that the size of the organization is positively related to innovation in the area of digital reference services. ${ }^{41}$ Damanpour and Childers studied public libraries by relating size to innovation. They found that library size, as defined by budget, was positively related to innovation; however, the rate of adoption among small to medium-sized libraries was rising faster than in large libraries. These researchers 
also found that the rate of innovation adoption was increasing from the 19751979 period to the 1980-1984 period. In a subsequent study of 75 public libraries, Damanpour found that specialization, functional differentiation, professionalism, size, and slack resources were better predictors of technical innovations than administrative innovations. ${ }^{42}$ In a more recent meta-analysis, Camisón-Zornoza and colleagues report that size is more positively related to innovation in service firms than in manufacturing firms. ${ }^{43}$

Innovation in Related Nonprofit Organizations. Given the relatively few empirical studies of libraries, it is useful to examine studies of other nonprofits in which the results might be generalizable to research libraries. High schools have both professional and staff employees and focus on education. In a particularly relevant study, Daft and Becker studied innovation in 13 high school districts in Illinois. Innovation was operationalized by asking senior teachers or administrators which innovations had been adopted and put to use in their district. In a multiple regression analysis, Daft and Becker found that one of the best predictors for innovation was organizational decentralization. Other indicators that were positively related to innovation included teacher professionalism, educational expenditures per pupil, and the positive attitude of elites (superintendent and school board members). ${ }^{44}$ In studying 88 primary and secondary schools, Koberg found that an uncertain environment and inadequate resources can precipitate broad changes in both structure and strategy, effects that can lead to innovation. ${ }^{45}$ Hage and Dewar studied 16 welfare organizations and found that both organizational complexity and elite values were positively related to innovation. Elite values were constructed based on positive views of change and were seen as slightly better predictors than organizational complexity. ${ }^{46}$ Jaskyte notes that there are only a handful of studies that have sought to identify predictors of innovation in government and nonprofit orga- nizations. Her study of a large network of nonprofit organizations found that three variables were significant predictors of administrative innovations (centralization, transformational leadership, and executive director job tenure), while transformational leadership was the only significant predictor of technical innovations. ${ }^{47}$

The previous studies focused on libraries and similar organizations, indicating some important trends. Organizational complexity as measured by professionalism and diversity of knowledge appear to relate positively to innovation. Organizational size as measured by budget also appears to be positively associated with innovation in libraries. Formal and hierarchical structures appear to restrict innovation activity. The effect of a leader's positive attitude toward change appears to transcend organizational types in having a positive impact on innovation.

\section{Theory and Propositions}

In this section, propositions are put forth that relate the institutional and service framework, organizational structure, and leadership to innovation. This more encompassing framework can lead to more consistent research results and important insights for practitioners within research libraries.

The Service Model and Factors Affecting the Radical-Incremental Continuum. According to Meyer and Rowan, institutionally controlled environments will buffer organizations from external turbulence where dramatic instability in products and policies become unlikely. This buffering mechanism increases the likelihood of change being predominantly incremental. ${ }^{48}$ Similarly, from a service perspective, the reverse product cycle (RPC) emphasizes the focus on incremental innovations that originate in nonprofits, largely through the transfer of information and communication technology products from outside agencies. Once information technology is transferred, it becomes a platform for implementing quality and efficiency improvements, both of which 
result primarily in incremental innovations. In an empirical study of hospitals by Salge and Vera, these researchers characterize the significant aspect of practice-based innovations that emanate from the tacit knowledge of practitioners and daily practice. These incremental improvements are largely process innovations that do not have a technology component. ${ }^{49}$ It is noteworthy that research libraries do, in fact, focus much of their effort on processes to provide high-quality service to their clients. In a conceptual paper, Benner and Tushman state that an increase in process management practices will promote incremental innovations while decreasing radical innovations. The rationale is quite intuitive in that process-focused activities stabilize resource allocation, tighten communication linkages, and restrict the types of changes that are permitted. ${ }^{50}$

Many of these observations are evident in the research library in which public service librarians are in daily contact with students and their respective academic departments-relationships that can lead to many incremental innovations. These service innovations are rarely of a radical nature, since a major change could create a service disruption or possibly confuse the client. ${ }^{51}$ As noted in figure 1, the external environment also has an impact on innovation. In their environmental framework, Damanpour and Gopalkrishnan have characterized educational institutions as existing in a stable and predictable environment. In a stable environment, the organization focuses primarily on the efficiency and quality of its operations, which leads to incremental innovations. ${ }^{52}$ These observations lead to the following proposition:

P1: Technical innovation activity in research libraries will be predominantly incremental as opposed to radical.

Organizational Structure-Bureaucracy (Centralization and Formalization). The dis- cussion of isomorphic forces by DiMaggio and Powell suggests that the norms and traditions of professionally based organizations lead to mimetic behavior and bureaucratization. In their study of the role of the external environment, Damanpour and Gopalakrishnan note that educational institutions have existed for many years in a relatively stable, predictable environment, a condition that leads to hierarchical, centralized organizational structures. Mussman uses Mintzberg's classification to suggest that different units in the library are either machine or professional bureaucracies. Much of the innovation literature has suggested that the effect of bureaucracy on innovation is largely negative. In their study of program change, Hage and Aiken found that centralization and formalization are both negatively associated with organizational change. ${ }^{53}$ In a study of English local political institutions, Walker found that formalization - the burden of rules and regulations - was negatively related to service innovations. ${ }^{54}$ In an empirical study, Dewar and Dutton found that a hierarchical, bureaucratic organization favors radical innovation, whereas flattened structures and power sharing favor incremental innovation. As noted previously, Daft and Becker found that decentralization (in other words, reduced organizational hierarchy) in high school districts was an important predictor of technical innovations. However, administrative innovations occurred more often in a centralized, top-down structure.

For public service in research libraries, the delivery of a high-quality, reliable service requires the practitioner to follow prescribed rules and guidelines. Library technical services are characterized by standards, controls, and structures that are necessary to deliver an efficient and high-quality product. These rules and the norms of the profession encourage conformity and discourage new ideas that might not be compatible with existing processes. As a consequence, it is expected that the practitioners working in technical 
and public service units will introduce incremental innovations that emanate from daily practice, tacit knowledge, and the interface to the public. Basically, as exemplified in the reverse product cycle, rules and procedures are established to incrementally improve library processes. These observations and the results from earlier empirical studies lead to the following propositions:

P2: In research libraries, formalization will be positively associated with technical, incremental innovations and negatively associated with technical, radical innovations.

P3: In research libraries, formalization will be positively associated with administrative innovations, both radical and incremental.

In a bureaucratic organization, the theoretical concept of centralization posits that the locus of authority and decision making resides with the leadership and managers of the organization. It seems obvious or intuitive that administrators - the leaders and managers of the organization - should take the initiative for creating administrative innovations. Administrative procedures are the purview of managers and are not likely to be of interest to members of the technical core. Although librarians have considerable autonomy in suggesting and implementing incremental innovations, the centralization concept suggests that the initiative for major change will originate with leadership. As a result, it is expected that centralization will positively affect radical, technical innovation in research libraries. The rationale is that organizational elites - the top management-are required to not only make a decision regarding a radical innovation, but they must also be engaged to properly marshal the resources necessary to implement the innovation. In contrast, the practitioners in the organization are close to the client and have significant autonomy in introducing incremental innovations.
In a study of nonprofit organizations, Jaskyte's findings support most of these observations. As noted in the literature review, she has found that centralization is significantly related to administrative innovations while transformational leadership was the only significant factor for technical innovations. ${ }^{55}$

From these observations and the reported research, the hierarchical structure of the organization is expected to impact both administrative innovations and the radical-incremental continuum, leading to the following hypotheses:

P4: In research libraries, centralization will be positively associated with administrative innovation, both radical and incremental.

P5: In research libraries, centralization will be positively associated with technical, radical innovations and not significantly related to technical, incremental innovations.

Organizational Structure-Complexity. Intuitively, the innovation-complexity association can be seen as originating in an extensive and diversified knowledge base resulting from many job types and different functional units, a structure resulting in new ideas that can ultimately lead to an innovative product or service. In a study of innovation in hospitals, Kimberly and Evanisko found that specialization, size, and functional differentiation are all positively related to technological innovation. ${ }^{56}$ Daft and Becker found that organizational complexity in high schools, as represented by teacher professionalism, has a substantial positive association with innovation. ${ }^{57}$ In a similar approach, Dewar and Dutton found that a principal predictor of radical innovations was the depth of knowledge resources as measured by the number of technical specialists. ${ }^{58}$ It is expected that the complexity dimension will be very important for nonprofits. The isomorphic forces described earlier produce homogeneous organizations in 
which members have similar educational background. A more diverse organization in terms of knowledge base and skills will lead to more innovative activity resulting in the following proposition:

P6: In research libraries, organizational complexity will be positively associated with technical innovations-both radical and incremental-and will have a stronger association with radical innovations.

\section{Leadership. Leaders of organizations} articulate strategy and prevent the organization from drifting in directions that have little promise. These leaders create a vision of the future that allows followers to understand what steps should be taken, helping the organization keep an eye on the vision while striking a balance between new opportunities and improving existing capabilities. ${ }^{59}$ Leaders, together with the leadership team, create vision and strategy, motivate followers, make changes in structure, and establish reward systems. A central concept of this study is that the leader at the top of the organization and the leadership team have a significant impact on organizational innovation.

Hambrick and Mason developed a model of how upper-echelon characteristics are reflected in organizational outcomes, suggesting that managerial characteristics will partially predict organizational performance levels. They argue that complex decisions, such as those regarding the strategy of the organization, are difficult to make based solely on technical and economic factors. For these more complex decisions, leaders are inclined to make decisions based on behavioral factors. In the proposed upperechelon model, Hambrick and Mason claim that observable managerial characteristics such as age and educational level can be considered indicators of cognitive characteristics such as knowledge about future events and alternatives. ${ }^{60}$

These researchers posit several important propositions regarding age, educa- tion, and tenure. A key concept is that a leader's ability to encourage creativity and innovation is dependent on certain characteristics of the leader. Mumford and Licuanan argued that leaders must possess substantial technical and professional expertise and substantial creative thinking skills to foster creativity in followers. ${ }^{61}$ In one of the earliest studies relating innovation to educational level, Mohr found that education level was only weakly related to innovation. ${ }^{62}$ Daft and Becker note that teacher professionalism was positively associated with innovation adoption: the more highly educated teachers are more knowledgeable about innovation and propose new ideas more frequently. ${ }^{63}$ Kimberly and Evanisko studied hospital innovation and found that a highly educated hospital administrator positively affected technological innovation. ${ }^{64}$ In the study of U.S. local government agencies by Damanpour and Schneider, the findings reveal a positive relationship between educational level and innovation. ${ }^{65}$ In studying drug and alcohol treatment centers, Davis found that the level of education is positively related to innovation awareness. ${ }^{66}$

Hambrick and Mason proposed that the amount but not the type of formal education of a manager or management team will be positively associated with innovation. ${ }^{67}$ Regarding educational level, the research library has consistently required that a professional librarian must have the master's degree in library science (MLS). A sampling of resumes available on the Internet suggests that most university librarians have the MLS but far fewer have a second master's degree or a PhD. Within the academic library environment, it is expected that a second master's degree or a $\mathrm{PhD}$ is especially important for innovation. Library leaders with these additional educational credentials are likely to be boundary scanners and will be more receptive to new ideas that originate outside the library profession. These leaders may also take on the role of idea champions to actually advocate and 
support the adoption and implementation of new ideas. Consistent with most of the earlier studies, it is expected that the level of education, specifically beyond the MLS, will have an impact on innovation and this impact will be stronger in supporting radical innovation.

The demographics of the library profession have been well documented. Wilder notes that librarians, particularly academic librarians, are older than other professionals in all but a few occupations. For the profession, about 75 percent of librarians are 45 years or older and the trend appears to be in the direction of increasing age, with significant aging occurring after $1990 .{ }^{68}$ It is expected that the effects of age and tenure will be most noticeable in the relationship to radical innovation. According to Hambrick and Mason, many years of inside service by top managers will be negatively related to strategic choices involving new terrain. ${ }^{69}$ Finkelstein and Hambrick studied executive team tenure in a sample of 100 industrial firms. These researchers found that tenure has a significant impact on strategy and performance with longtenured teams following more persistent strategies that resist change. ${ }^{70}$ Koberg et al. have reported that younger leaders are more likely to embrace radical innovations, since these individuals are less committed to the status quo and traditional rules. However, one should also expect to find a U-shaped relationship where the very young leader will want to adhere to established protocols to build credibility. ${ }^{71}$ Regarding incremental innovations, academic librarians, especially in the public services units, have considerable autonomy in their specific disciplines and as liaisons to their respective academic departments. It is expected that much of the incremental innovation emerges from practice and the liaison relationship and is relatively unaffected by the leader of the organization. These aspects of formal education and leadership demographics lead to the following propositions:
P7: In research libraries, leaders' formal education beyond the MLS will be positively related to radical innovation.

P8: In research libraries, the age, tenure in the library, and tenure in the profession of the leadership team will be positively related to incremental innovations and negatively related to radical innovations.

\section{Implications for Research Libraries}

This study has focused on the institutional framework, organizational structure, and leadership in research libraries to put forth propositions that can be tested in empirical studies. What are the implications of these propositions for research libraries? Propositions P1 and P2 suggest that technical innovation activity in libraries is predominantly incremental, while radical innovations emanate primarily from the administrative core of the research library (P4). If technical expertise resides in the technical core, then why are there relatively few major innovations emerging from this core group of people? The answer may lie in the formalization of the library-the rules, processes, and structures that restrict the free flow of ideas (proposition P4). For a sustained innovative activity, all organizational members should feel empowered to suggest innovations not only within their sphere of responsibility, but also innovations that might be relevant in other units or have a multiunit impact. For organizational members to initiate or pursue more radical concepts, they will require the organizational and psychological support that leaders can provide. Alternatively, it is possible that the technical core does not have the right technical expertise. Radical innovations are based in new knowledge that may not be part of the knowledge base of the traditional library. The restrictions on radical innovative activity are seen as most consequential in the area of developing new 
knowledge, knowledge that originates outside the professional associations and the curricula of library schools. Less centralization and increasing the diversity of knowledge and skills will help to create a more innovative climate within the library (P5, P6). A critical aspect of knowledge growth is the leaders' ability to create and articulate a knowledge strategy that embraces both exploratory work and the support of existing services. ${ }^{72}$

Propositions P7 and P8 are perhaps most problematic for the academic library profession. Changing the tenure and educational profile of the leadership team is most difficult and cannot be done quickly. However, vacancies and new appointments represent significant opportunities to alter the profile of the leadership team to create a culture that can bring in new ideas and pursue quite different business models.

Taken as a whole, these propositions suggest that innovations emanating from research libraries will be mostly incremental. The traditions and norms of the profession will continue to envelope the library in the "iron cage" of institutional nonprofits, making it difficult to launch more radical innovations.$^{73}$ However, the continued turbulence in the external environment has an opposite effect and can act for major change, resulting in more radical innovations. Economic and financial pressures will be significant factors. Perhaps this is what Daniel Greenstein, vice provost for academic planning and programs in the University of California System, had in mind as quoted from a recent publication: "The university library of the future will be sparsely staffed, highly decentralized, and have a physical plant consisting of little more than special collections and study areas."74 This view suggests that the research library is beginning a declining trend that will end in irrelevance. Trends in academic libraries showing a decline in the percentage of the parent institution's budget provide support for Greenstein's view. For example, Allen and Dickie report that the budgets of 88 ARL libraries fell steadily in a decade (1982 to 1992) from 3.91 percent to 3.32 percent of the university's education and general budget. ${ }^{75}$ This continued economic turbulence remains a significant factor in the first decade of the 21st century.

The rapid pace of technological change is another major external factor that will act for change in the research library. As an example, two recent articles predict the end of book publishing as we know it today, a trend driven by digitization, print-on-demand technology, mobile technology, and the associated self-publishing initiative. The Bowker publishing company has reported that more than two-thirds of the books published in 2010 in the United States were self-published. ${ }^{76}$ Epstein predicts that a universal catalog of print-ready digital books will soon be a reality, a collaborative task that is already well under way. ${ }^{77}$ These technical innovations are turning the book publishing business upside down and are having a similar impact on research libraries. Lesk predicts that the declining costs of books via self-publishing and print-on-demand devices will result in more library users willing to buy an inexpensive book rather than borrow one from the library. ${ }^{78}$ The challenge and opportunity for the library leader is to take advantage of these technological discontinuities rather than having to react to a change that has already impacted the library.

How can these observations and trends be interpreted within the context of organizational innovation and the research library? There is an interesting conundrum at play, where external factors are acting for major change whereas many of the organizational and professional factors resist change. For library leaders, this conundrum represents a huge challenge and also a significant opportunity. The major new technical innovations will originate externally and be transferred into the library if there is a receptive positive attitude and organizational culture. For a sustained innovative culture, library leaders can effectively influence innovation in their organizations by focusing 
on administrative innovations. These innovations might appear in the vision and strategy of the organization, the organizational structure to support both incremental and discontinuous innovations, and the reward systems that will encourage innovative thinking.

What might these administrative innovations look like? Clearly the more formalized structure of the traditional library provides the rules and processes that are necessary to deliver an efficient, highquality service to clients. A radical library administrative innovation might be one in which dual organizational structures can reside side-by-side in the library-one supporting the traditional services while another is exploring potentially new services. In a case study of 15 business units in 9 different industries, $\mathrm{O}^{\prime}$ Reilly and Tushman found that 90 percent of the organizations with structurally independent research units achieved their goals while simultaneously helping the organization maintain or improve performance. ${ }^{79}$ As noted in the literature review, it is important to buffer this exploratory work from the process-oriented work that restricts the free flow of ideas. A management innovation might establish an explicit budget that is dedicated to R\&D. Related to the free flow of ideas, it is important to improve the reward system, not only to reward new and more novel ideas, but also to find ways to learn from failures and support those organizational members who participated in the failed project.

There remain two factors that were not addressed in the propositions and that will require longitudinal studies to understand more fully. The first of these is the pace of innovation. Libraries are accustomed to existing in a relatively stable environment. The external factors discussed briefly above suggest that the research library exists in a more unstable environment brought about by rapid technological innovation and pressures from the economic, financial, and political sectors of our society. One can speculate that the library will need to have an in- creased sense of urgency in responding to the external environment or, alternatively, be left to follow whatever the external environment dictates. The second factor involves the ability to sustain both incremental and radical innovation streams over time. In effect, both exploratory and exploitative activity must become a way of life for research libraries.

\section{Conclusion}

The theoretical framework in this study suggests that the institutional nonprofit organization innovates differently from other sectors. According to DiMaggio and Powell, institutional nonprofits, such as research libraries, will become homogenized - resembling each other in structure, culture, and outcomes. This homogenization results in reduced variation and in many incremental innovations that are transferred and exchanged among similar libraries. In research libraries, the traditional bureaucratic tendencies imply that radical innovations will typically emanate from the administrative core. However, it can also be postulated that the more turbulent external environment will lead to the emergence of more organic structures. These organic structures hold out the promise of members of the technical core initiating radical innovations that originate from knowledge bases quite distinct from those of the traditional library institution. DiMaggio and Powell (1983) use the metaphor of the "iron cage," suggesting that the homogenization brought about by institutional forces is irreversible and results in incremental, normatively sanctioned innovations. This hypothesis remains a significant challenge for library leaders who want to create an innovative organization. Leadership is clearly important in the creation and articulation of vision and strategy and the resulting impact on structure and culture. The organizational dynamic and conundrum for the leader resides in the forces of the external environment and the organizational structure. The turbulence in the external environment acts in favor of change, while 
the bureaucratic, hierarchical structure of the library resists change. The leader's challenge is to strike a balance between these opposing forces to create an organization that is flexible and can engage in exploratory activity while also supporting the traditional library functions that are important to provide high-quality service to the university community.

The propositions in this study characterize some of the major obstacles to change and innovation in research libraries. These propositions also suggest areas for further empirical studies that will provide insight into how research libraries can transform themselves to meet the needs of the 21st-century research university. To fully understand innovation processes in research libraries, scholars will need to address a multiplicity of factors including leadership, the organizational structure, and the unique institutional framework of the modern research university.

\section{Notes}

1. Although the focus in this study is on research libraries, it is expected that most of the propositions will also apply to the larger community of academic libraries.

2. Richard L. Daft and Selwyn W. Becker, Innovation in Organizations (New York: Elsevier, 1978), 6-7.

3. Ronald C. Jantz, "Innovation in Academic Libraries: An Analysis of University Librarians' Perspectives," Library and Information Science Research, 34 (2012): 9-11.

4. Everett M. Rogers, Diffusion of Innovations, 5th ed. (New York: Free Press, 2003), 404.

5. Richard L. Daft, "A Dual-Core Model of Organizational Innovation," Academy of Management Journal 21 (1978): 197-98; Fariborz Damanpour, "Bureaucracy and Innovation Revisited: Effects of Contingency Factors, Industrial Sectors, and Innovation Characteristics," Journal of High Technology Management Research 7 (1996): 153.

6. Franco Malerba, "Sectoral Systems: How and Why Innovation Differs across Sectors," in The Oxford Handbook of Innovation, eds. Jan Fagerberg, David C. Mowery, and Richard R. Nelson (Oxford: Oxford University Press, 2005), 381.

7. Faiz Gallouj and Maria Savona, "Innovation in Services: A Review of the Debate and a Research Agenda," Journal of Evolutionary Economics 19 (2009): 152.

8. Ian Miles, "Innovation in Services," in The Oxford Handbook of Innovation, eds. Jan Fagerberg, David C. Mowery, and Richard R. Nelson (Oxford: Oxford University Press, 2005), 433.

9. Ibid., 436 .

10. Richard Barras, "Toward a Theory of Innovation in Services," Research Policy 15 (1986): 161-62.

11. Christine Hipp and Hariolf Grupp, "Innovation in the Service Sector: The Demand for Servicespecific Innovation Measurement Concepts and Typologies," Research Policy 34 (2005): 519-21.

12. Gallouj and Savona, "Innovation in Services," 156-57.

13. Paul J. Dimaggio and Walter W. Powell, "Introduction," in The New Institutionalism in Organizational Analysis, eds. Paul J. Dimaggio and Walter W. Powell (Chicago: University of Chicago Press, 1991), 2; Ingo Bode, "Flexible Response in Changing Environments: The German Third Sector Model in Transition," Nonprofit and Voluntary Sector Quarterly 32 (2003): 1-2.

14. Paul J. Dimaggio and Walter W. Powell, "The Iron Cage Revisited: Institutional Isomorphism and Collective Rationality in Organizational Fields," American Sociological Review 48 (1983): 150-54.

15. Ibid, 152.

16. Ibid, 155 .

17. Fariborz Damanpour and Shanthi Gopalakrishnan, "Theories of Organizational Structure Innovation Adoption: The Role of Environmental Change," Journal of Engineering and Technology Management 15 (1998): 5-10.

18. Daft, "A Dual-Core Model of Organizational Innovation," 195-96.

19. Gerald Zaltman, Robert Duncan, and Jonny Holbeck, Innovations \& Organizations (Malabar, Fla.: Robert E. Krieger Publishing, 1984), 23-30; Walter Nord and Sharon Tucker, Implementing Routine and Radical Innovations (Lexington, Mass.: Lexington Books, 1987).

20. Robert B. Duncan, “The Ambidextrous Organization: Designing Dual Structures for Innovation," in The Management of Organization Design: Strategies and Implementation, eds. Ralph H. Killman, Louis R. Pondy, and Dennis P. Slevin (New York: North-Holland, 1976), 168-70.

21. Daft, "A Dual-Core Model of Organizational Innovation," 195-96.

22. Fariborz Damanpour, "Organizational Complexity and Innovation: Developing and Test- 
ing Multiple Contingency Models," Management Science 42 (1996): 698.

23. Zaltman, Duncan, and Holbeck, Innovations \& Organizations, 24.

24. The term "radical" has a somewhat pejorative connotation. Although other terms such as "nonincremental" and "discontinuous" have been used more recently, this study will retain the term "radical" as being less rhetorically awkward.

25. Duncan, "The Ambidextrous Organization," 168-70.

26. Tom Burns and George Macpherson Stalker, The Management of Innovation (London: Tavistock, 1961), 104-08.

27. Damanpour and Gopalakrishnan, “Theories of Organizational Structure Innovation Adoption," 11-16.

28. Zaltman, Duncan, and Holbeck, Innovations \& Organizations, 179.

29. Gary Hamel and C.K. Prahalad, Competing for the Future: Breakthrough Strategies for Seizing Control of Your Industry and Creating the Markets of Tomorrow (Boston: Harvard Business School Press, 1994), 131-33.

30. Zaltman, Duncan, and Holbeck, Innovations \& Organizations, 138.

31. Jerald Hage and Michael Aiken, Social Change in Complex Organizations (New York: Random House, 1970), 43.

32. Duncan, "The Ambidextrous Organization," 168-70.

33. Fariborz Damanpour and Deepa Aravind, "Organizational Structure and Innovation Revisited: From Organic to Ambidextrous Structure," in Handbook of Organizational Creativity, ed. Michael D. Mumford (Elsevier: Academic Press, 2012): 502-503.

34. Rogers, Diffusion of Innovations, 15.

35. Louis G. Tornatzky and Katherine J. Klein, "Innovation Characteristics and Innovation Adoption-Implementation: A Meta-analysis of Findings," IEEE Transactions on Engineering Management 29 (1982): 40-41.

36. Judy Reynolds and Jo Bell Whitlatch, "Academic Library Services: The Literature of Innovation," College \& Research Libraries 46 (1985): 402.

37. John M. Budd, The Academic Library: Its Context, Its Purpose, and Its Operation (Englewood, Colo.: Libraries Unlimited, 1998), 166.

38. Klaus Musman, “The Diffusion of Innovation in Libraries," Libri 32 (1982): 269.

39. Helen Howard, "The Relationship between Certain Organizational Variables and the Rate of Innovation in Academic Libraries" (PhD dissertation, Rutgers, The State University of New Jersey, New Brunswick, New Jersey, 1977).

40. Rena K. Fowler, "The University Library as Learning Organization for Innovation: An Exploratory Study," College \& Research Libraries 59 (1998): 225-27.

41. Marilyn Domas White, "Diffusion of an Innovation: Digital Reference Service in Carnegie Foundation Master's (comprehensive) Academic Institution Libraries," Journal of Academic Librarianship 27 (2001): 176.

42. Fariborz Damanpour and Thomas Childers, "The Adoption of Innovation in Public Libraries," Library \& Information Science Research 7 (1985): 242; Fariborz Damanpour, "The Adoption of Technological, Administrative, and Ancillary Innovations: Impact of Organizational Factors," Journal of Management 13 (1987): 682-85.

43. Cesar Camisón-Zornoza, Rafael Lapiedra-Alcamí, Mercedes Segarra-Ciprés, and Montserrat Boronat-Navarro, "A Meta-analysis of Innovation and Organizational Size," Organization Studies 25 (2004): 351.

44. Daft and Becker, Innovation in Organizations, 37, 55-60.

45. Christine S. Koberg, "Resource Scarcity, Environmental Uncertainty, and Adaptive Organizational Behavior," Academy of Management Journal 30 (1987): 804-05.

46. Jerald Hage and Robert Dewar, "Elite Values versus Organizational Structure in Predicting Innovation," Administrative Science Quarterly 18 (1973): 282, 284-86.

47. Kristina Jaskyte, "Predictors of Administrative and Technological Innovations in Nonprofit Organizations," Public Administration Review 71 (2011): 79.

48. John W. Meyer and Brian Rowan, "Institutional Organizations," in The New Institutionalism in Organizational Analysis, eds. Paul J. DiMaggio and Walter W. Powell (Chicago: University of Chicago Press, 1991), 52.

49. Torsten Oliver Salge and Antonio Vera, "Hospital Innovativeness and Organizational Performance: Evidence from English Public Acute Care," Health Care Management Review 34 (2009): 56.

50. Mary J. Benner and Michael L. Tushman, "Exploitation, Exploration, and Process Management: The Productivity Dilemma Revisited," Academy of Management Review 28 (2003): 238.

51. Fariborz Damanpour, Richard M. Walker, and Claudia N. Avellandea, "Combinative Effects of Innovation Types and Organizational Performance: A Longitudinal Study of Service Organizations," Journal of Management Studies 46 (2009): 657.

52. Damanpour and Gopalakrishnan, "Theories of Organizational Structure Innovation Adop- 


\section{A Framework for Studying Organizational Innovation in Research Libraries 541}

tion," 12.

53. Damanpour and Gopalakrishnan, "Theories of Organizational Structure Innovation Adoption," 12; Musman, "The Diffusion of Innovation," 269; Jerald Hage and Michael Aiken, "Program Change and Organizational Properties: A Comparative Analysis," American Journal of Sociology 72 (1967): 510-11; Damanpour, "Bureaucracy and Innovation Revisited," 153; Hage and Aiken, Social Change, 32-44;

54. Richard M. Walker, "An Empirical Evaluation of Innovation Types and Organizational and Environmental Characteristics: Towards a Configuration Approach," Journal of Public Administration Research and Theory 18 (2008): 603-07.

55. Kristina Jaskyte, "Predictors of Administrative and Technological Innovations in Nonprofit Organizations," Public Administration Review 71 (2011): 77.

56. John R. Kimberly and Michael J. Evanisko, “Organizational Innovation: The Influence of Individual, Organizational, and Contextual Factors on Hospital Adoption of Technological and Administrative Innovations," Academy of Management Journal 24 (1981): 701-08.

57. Daft and Becker, Innovation in Organizations, 37, 81.

58. Robert D. Dewar and Jane E. Dutton, "The Adoption of Radical and Incremental Innovations: An Empirical Analysis," Management Science, 32 (1986): 1429.

59. Rosabeth Moss Kanter, The Change Masters (New York: Simon and Schuster, 1983), 294-95.

60. Donald C. Hambrick and Phyllis A. Mason, "Upper Echelons: The Organization as a Reflection of Its Top Managers," Academy of Management Review 9 (1984): 197-201.

61. Michael D. Mumford, Ginamarie M. Scott, Blaine Gaddis, and Jill M. Strange, "Leading Creative People: Orchestrating Expertise and Relationships," The Leadership Quarterly 13 (2002): 712-13; Michael D. Mumford and Brian Licuanan, "Leading for Innovation: Conclusions, Issues, and Directions," Leadership Quarterly 15 (2004): 164-66.

62. Lawrence B. Mohr, "Determinants of Innovation in Organizations," American Political Science Review 63 (1969): 118.

63. Daft and Becker, Innovation in Organizations, 37, 80.

64. Kimberly and Evanisko, "Organizational Innovation," 702.

65. Fariborz Damanpour and Marguerite Schneider, "Characteristics of Innovation and Innovation Adoption in Public Organizations: Assessing the Role of Managers," Journal of Public Administration Research and Theory 19 (2009): 514.

66. Carolyn D. Davis, “Organizational Innovation: The Role of Top Management in Different Stages of Innovation Implementation" (PhD dissertation, Georgia Institute of Technology, retrieved January 28, 2011), 52-53.

67. Hambrick and Mason, “Upper Echelons," 197-201.

68. Stanley Wilder, The Age Demographics of Academic Librarians: A Profession Apart (Binghamton, N.Y.: Haworth Information Press, 1999), 1.

69. Hambrick and Mason, “Upper Echelons," 200.

70. Sydney Finkelstein \& Donald C. Hambrick, "Top-Management-Team Tenure and Organizational Outcomes: The Moderating Role of Managerial Discretion," Administrative Science Quarterly 35 (1990): 486-88.

71. Christine S. Koberg, Dawn R. Detienne, and Kurt A. Heppard, "An Empirical Test of Environmental, Organizational, and Process Factors Affecting Incremental and Radical Innovation," Journal of High Technology Management Research 14 (2003): 38.

72. Paul E. Bierly and Paula S. Daly, "Alternative Knowledge Strategies, Competitive Environment, and Organizational Performance in Small Manufacturing Firms," Entrepreneurship Theory and Practice 31 (2007): 494-96.

73. Dimaggio and Powell, "The Iron Cage Revisited," 150.

74. Daniel Greenstein, "Libraries of the Future," in Inside Higher Ed (2009), available online at www.insidehighered.com/news/2009/09/24/libraries [accessed 17 July 2012].

75. Frank R. Allen and Mark Dickie, "Toward a Formula-Based Model for Academic Library Funding: Statistical Significance and Implications of a Model Based upon Institutional Characteristics," College \& Research Libraries 72, no. 4 (2007): 171.

76. Michael Lesk, "Reading: From Paper to Pixels," IEEE Security and Privacy, 9 (2011): 78.

77. Jason Epstein, “The End of the Gutenberg Era," Library Trends 57, no. 1 (2008): 15.

78. Lesk, "Reading: From Paper to Pixels," 78.

79. Charles O'Reilly III and Michael L. Tushman, “The Ambidextrous Organization," Harvard Business Review, 82 (Apr. 2004): 76; Michael L. Tushman, Wendy Smith, Robert Wood, George Westerman, and Charles A. O'Reilly, "Innovation Streams and Ambidextrous Organizational Designs: On Building Dynamic Capabilities," available online at http://web.mit.edu/sloan/osgseminar/f02_docs/TushmanEtAl_2002.pdf [accessed 17 July 2012]. 


\section{"An investment in knowledge pays the best interest."}

- Benjamin Franklin

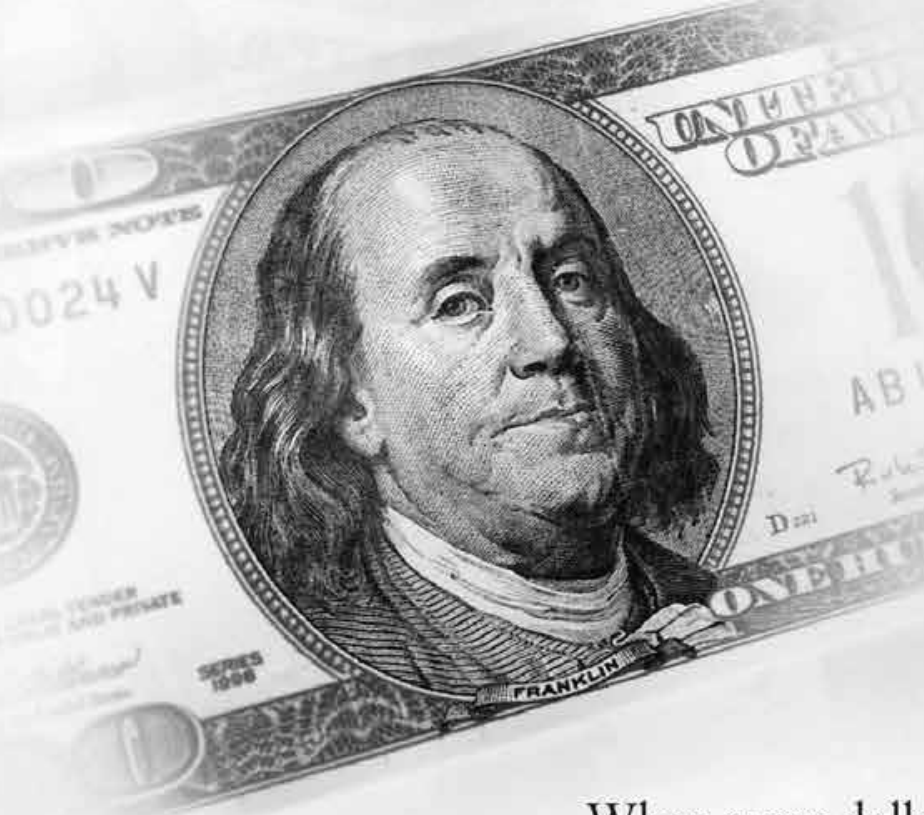

When every dollar counts, get the most out of your budget with Choice Reviews Online.

The perfect companion to a CHOICE print subscription:

- Access to over 145,000 CHOICE reviews

- Download, print or e-mail search results

- Ability to create a customized profile

- Create, save and e-mail lists

- Search all CHOICE content

- View exclusive online material

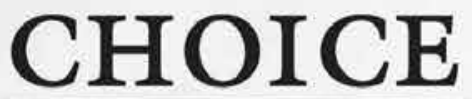

R E V I E W S O N L I N E

Choice is now on Facebook! Become a fan now by searching Choice Reviews Online on your Facebook page.

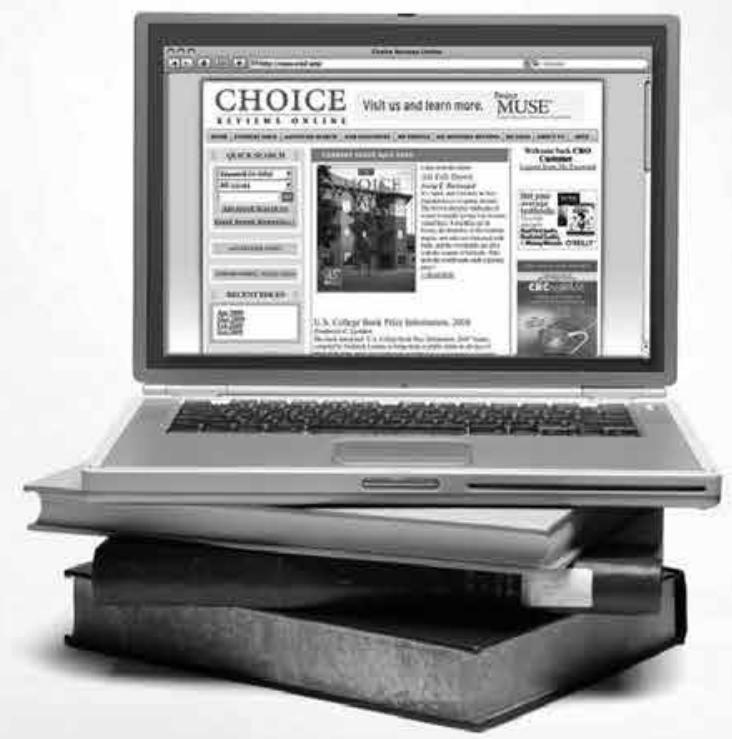

